\title{
Can We Identify Patients with High Risk of Osteoarthritis Progression Who Will Respond to Treatment? A Focus on Epidemiology and Phenotype of Osteoarthritis
}

\author{
Olivier Bruyère $\cdot$ Cyrus Cooper $\cdot$ Nigel Arden $\cdot$ Jaime Branco $\cdot$ Maria Luisa Brandi · \\ Gabriel Herrero-Beaumont · Francis Berenbaum • Elaine Dennison · Jean-Pierre Devogelaer • \\ Marc Hochberg • John Kanis • Andrea Laslop • Tim McAlindon - Susanne Reiter • Pascal Richette • \\ René Rizzoli $\cdot$ Jean-Yves Reginster
}

Published online: 21 February 2015

(C) The Author(s) 2015. This article is published with open access at Springerlink.com

\begin{abstract}
Osteoarthritis is a syndrome affecting a variety of patient profiles. A European Society for Clinical and Economic Aspects of Osteoporosis and Osteoarthritis and the European Union Geriatric Medicine Society working meeting explored the possibility of identifying different patient profiles in osteoarthritis. The risk factors for the development of osteoarthritis include systemic factors (e.g., age, sex, obesity, genetics, race, and bone density) and local biomechanical factors (e.g., obesity, sport, joint injury, and muscle weakness); most also predict disease progression, particularly joint injury, malalignment, and
\end{abstract}

O. Bruyère $(\bowtie) \cdot$ J.-Y. Reginster

Department of Public Health, Epidemiology and Health

Economics, University of Liège, CHU Sart-Tilman B23,

4000 Liège, Belgium

e-mail: olivier.bruyere@ulg.ac.be

C. Cooper - N. Arden · E. Dennison

MRC Lifecourse Epidemiology Unit and NIHR Nutrition

Biomedical Research Centre, University of Southampton,

Southampton, UK

C. Cooper $\cdot$ N. Arden

Oxford NIHR Musculoskeletal Biomedical Research Unit,

University of Oxford, Oxford, UK

J. Branco

CEDOC, Department of Rheumatology, Faculdadede Ciências Médicas, Universidade Novade Lisboa, CHLO, EPE, Hospital Egas Moniz, Lisbon, Portugal

\section{L. Brandi}

Metabolic Bone Unit, Department of Surgery and Translational Medicine, University of Florence, Florence, Italy

G. Herrero-Beaumont

Department of Rheumatology, Bone and Joint Research Unit, IIS-Fundación Jiménez Díaz, UAM, Fundación Jiménez Díaz, Madrid, Spain synovitis/effusion. The characterization of patient profiles should help to better orientate research, facilitate trial design, and define which patients are the most likely to benefit from treatment. There are a number of profile candidates. Generalized, polyarticular osteoarthritis and local, monoarticular osteoarthritis appear to be two different profiles; the former is a feature of osteoarthritis comorbid with inflammation or the metabolic syndrome, while the latter is more typical of post-trauma osteoarthritis, especially in cases with severe malalignment. Other biomechanical factors may also define profiles, such

\section{F. Berenbaum}

Department of Rheumatology, AP-HP, Saint-Antoine Hospital, Pierre and Marie Curie University, Paris, France

J.-P. Devogelaer

Department of Rheumatology, Saint-Luc University Hospital, Université Catholique de Louvain, Brussels, Belgium

\section{Hochberg}

Departments of Medicine and Epidemiology and Public Health, University of Maryland School of Medicine, Baltimore, MD, USA

J. Kanis

WHO Collaborating Centre for Metabolic Bone Diseases, University of Sheffield Medical School, Sheffield, UK

A. Laslop

Scientific Office, Austrian Agency for Health and Food Safety (AGES), Vienna, Austria

T. McAlindon

Division of Rheumatology, Tufts Medical Center, Boston, MA, USA

S. Reiter

Bundesinstitut für Arzneimittel und Medizinprodukte, Bonn, Germany 
as joint malalignment, loss of meniscal function, and ligament injury. Early- and late-stage osteoarthritis appear as separate profiles, notably in terms of treatment response. Finally, there is evidence that there are two separate profiles related to lesions in the subchondral bone, which may determine benefit from bone-active treatments. Decisions on appropriate therapy should be made considering clinical presentation, underlying pathophysiology, and stage of disease. Identification of patient profiles may lead to more personalized healthcare, with more targeted treatment for osteoarthritis.

\section{Key Points}

A range of factors affect pathogenesis, presentation, and prognosis of osteoarthritis.

These factors could have an impact on response to symptomatic or structural treatments for osteoarthritis.

There is some evidence that patients with early disease respond better to pharmacological treatments for osteoarthritis than those with late disease.

Treatment decisions should be made considering clinical presentation, underlying pathophysiology, and the stage of disease.

\section{Introduction}

Osteoarthritis is progressive chronic disease potentially affecting every articular tissue, and may potentially lead to joint failure. It has heterogeneous manifestations, and does not always have the same appearance in all patients. Indeed, osteoarthritis may present differently in men and women [1, 2], in patients with or without trauma, in athletes, or in obese patients. This raises the possibility that osteoarthritis patients with different profiles could require different treatments.

The European Society for Clinical and Economic Aspects of Osteoporosis and Osteoarthritis (ESCEO) has

\section{P. Richette}

Université Paris 7, UFR médicale, Assistance Publique-Hôpitaux de Paris, Hôpital Lariboisière, Fédération de Rhumatologie, Paris Cedex, France

\section{R. Rizzoli}

Division of Bone Diseases, Geneva University Hospital and Faculty of Medicine, Geneva, Switzerland already explored a variety of pivotal issues in osteoarthritis, including the question of how best to define responders to treatment for drug development [3], and the value of biomarkers and magnetic resonance imaging (MRI) in the diagnosis of the disease and the prediction of the hard outcome of joint replacement surgery $[4,5]$. In a new meeting in October 2013, an ESCEO-EUGMS (European Union Geriatric Medicine Society) working group discussed the possibility of identifying patients who would benefit most from treatment for osteoarthritis. The hypothesis discussed was that there may be different patient profiles according to mechanical or systemic features of the disease, or stage of the disease. This may have a variable impact on how patients react to treatments, and possibly even provide an explanation for the failure of clinical trials in osteoarthritis. Indeed, personalized medicine may prove to be advantageous in osteoarthritis insofar as it is a heterogeneous disease, with variable progression, and there is no standardized treatment that works in all patients [6]. The ultimate aim of these discussions is to lead to a more personalized clinical approach and cost-effective care for patients with osteoarthritis. This article is a summary of these discussions.

\section{Process and Outcomes}

We identified relevant articles, reviews, and abstracts in a search of PubMed/MEDLINE and EMBASE for Englishlanguage articles published between 1990 and October 2013. The initial search strategy included the terms osteoarthritis, risk factor, predictor, progression, guidelines, biomarkers, MRI, and phenotype, and yielded 463 items. Separate subsearches were also performed using a crosssearch of the above terms combined, and additional references were selected from the reference lists of selected articles and the presentations made during the working meeting. The narrative is therefore largely based upon expert opinion. Overall, 73 relevant items were selected by the authors according to their quality and pertinence for discussion by the ESCEO working group.

\subsection{Epidemiology and Risk Factors for Progression}

The general definition of osteoarthritis is a group of overlapping disorders with similar structural and clinical outcomes [7]. Indeed, osteoarthritis can affect articular cartilage, subchondral bone, synovium, meniscus, muscle, capsule, and ligaments. This definition of osteoarthritis may be important for the characterization of patient profiles, since it determines what sort of information is to be captured, i.e., structural, clinical, or surgical. Osteoarthritis has been classified into three subsets according to distinct 
etiological, clinical, and therapeutic characteristics: estrogen deficiency-related, genetically-induced, and age-related (Fig. 1) [1, 2]. This proposal is based on the etiology and pathogenesis of osteoarthritis [2], and combines the three main biological processes crucial for the development of osteoarthritis, together with additional risk factors such as obesity, the metabolic syndrome, and trauma. Understanding the pathogenesis of the disease is important for determining patient profiles in order to establish rational treatment in osteoarthritis. Another important consideration is that osteoarthritis is usually an insidiously progressive disease, and a patient's profile may evolve over the course of the disease [8]. It has been proposed that all of the clinical forms are interchangeable in the early stages of disease and may appear as differing clinical profiles in various tissues [9]. In more advanced disease, clinical and imaging presentations become more generalized and profiles may overlap.

In the research setting, osteoarthritis is generally classified radiographically, most typically using the KellgrenLawrence (KL) grading system [10, 11]. Although the correlation is not always linear [12,13], the osteoarthritis patients with the most pain tend to have the highest KL grades.

Osteoarthritis has a high incidence. A recent study in a Spanish population including more than 3 million individuals reported incidence rates of clinically diagnosed osteoarthritis of 6.5, 2.1, and 2.4 per 1,000 person-years for knee, hip, and hand, respectively [14]. The incidence of osteoarthritis increases with age, rising sharply beyond the age of 50 years and leveling off after the age of 80 years $[7,14-16]$. It is considerably more common in women than in men $[7,15,16]$. For example, in the Spanish study, the incidence rate of knee osteoarthritis in women was 8.3 per 1,000 person-years versus 4.6 per 1,000 person-years for men [14]. In view of the high prevalence and high cost of the surgical consequences of joint failure, osteoarthritis constitutes a major healthcare burden. The situation may even be worsening, since the rates of total hip replacement have increased and there are signs that joint replacement may be occurring at an earlier age [17]. The notion of healthcare burden is also important since patients with osteoarthritis are at higher risk for mortality than the general population, and there have been calls for a more unified approach to healthcare in these patients, including effective management of cardiovascular risk factors and co-morbidities [18, 19].

There are many risk factors for osteoarthritis, including systemic factors, such as age, sex, body mass index (and obesity), genetic factors, bone density, and estrogen status, and local biomechanical factors, such as obesity, physical activity or occupation, intense sporting activity, joint injury or deformity, and muscle weakness [7]. Some of these are also risk factors for progression of the disease. The three risk factors that appear to most consistently predict progression are obesity, generalized osteoarthritis, and

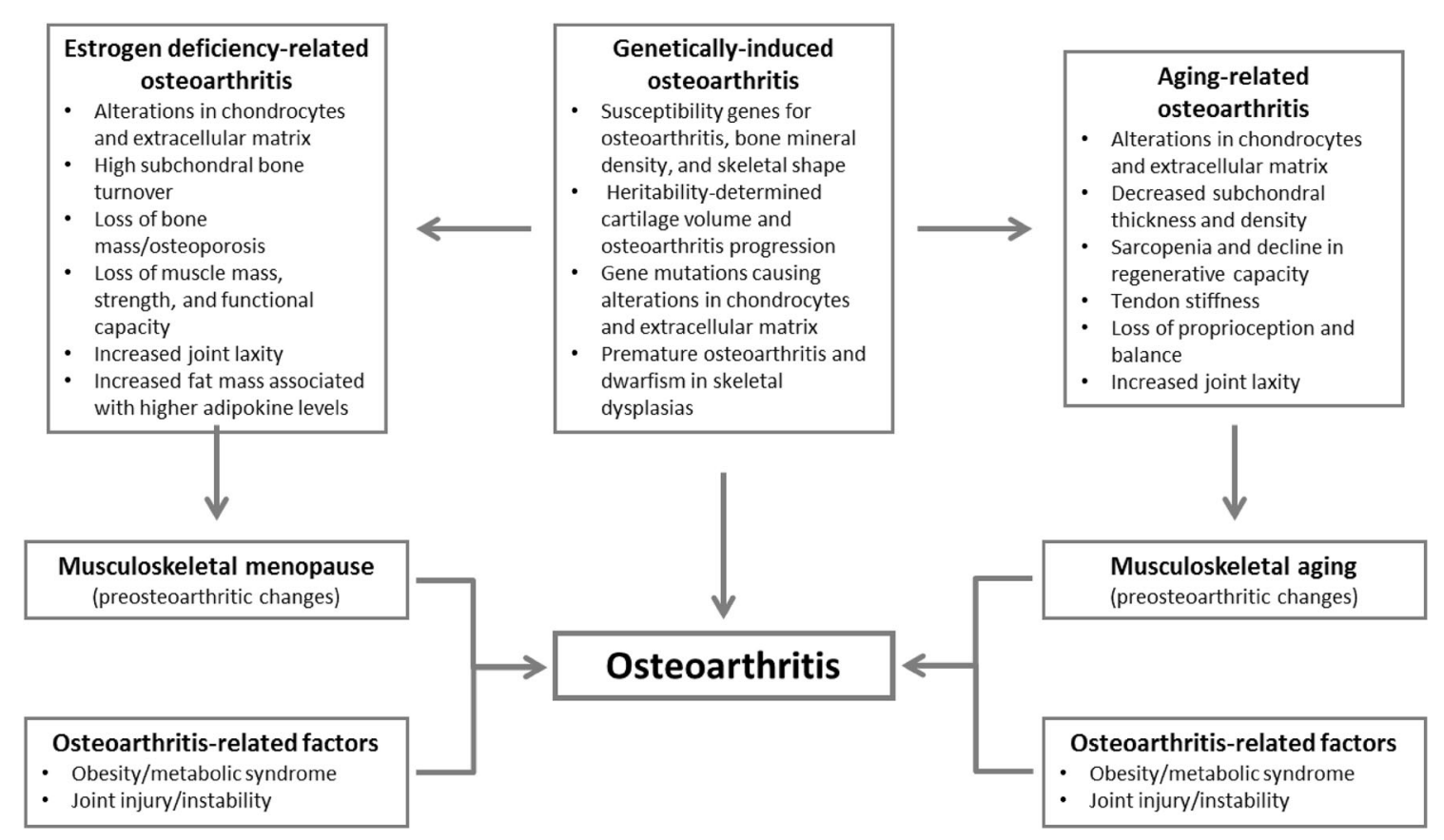

Fig. 1 Three subsets of osteoarthritis with distinct etiological, clinical, and therapeutic characteristics. Adapted from Herrero-Beaumont et al. [2], with permission 
synovitis/effusion [20]. Joint space narrowing over 5 years has recently been demonstrated to predict future knee replacements up to 15 years later [21, 22]. There are many epidemiological studies on progression of osteoarthritis. In one analysis performed in the Chingford Women's Study [23], the progression of radiographic knee osteoarthritis, i.e., KL grade, was recorded in a sample of 561 patients. Although more than half of patients had no progression with stable KL grades over 15 years, patients with KL grade 1 were twice as likely to progress as those with $\mathrm{KL}$ grade 0 [24]. While the evidence points to a rapid progression of patients with early disease, it should be treated with caution due to the possibility of collider bias, which is a potential confounder in any analysis involving selection of patients at baseline on the basis of a characteristic that is also a risk factor.

Current treatment guidelines in osteoarthritis generally agree that it requires a combination of non-pharmacological and pharmacological modalities [25-31]. Management should start with non-pharmacological therapy, and if symptoms persist a stepwise increase in treatment intensity should follow, starting with over-the-counter treatments, then prescription treatments for pain control, and then, if needed, referral for surgery; opioid analgesics are generally reserved for patients who cannot receive surgery. Regulatory guidelines are also available for drug development in the symptomatic and structural management of osteoarthritis [32]. None of these guidance documents provide any information on which patients should be treated.

\subsection{Identification of Patient Profiles in Osteoarthritis}

The characterization of patient profiles appears as an important priority for osteoarthritis for a number of reasons. First, it would help to better orientate research and understand the disease, which would in turn improve its management. Second, it would facilitate the design of randomized clinical trials in the field and the development of new pharmacological strategies. Third, it would help to better determine which patients are the most likely to benefit from which treatment, leading to more personalized medicine and more effective use of healthcare [6].

Osteoarthritis is a heterogeneous disorder and the various patient profiles will be influenced by many different factors (Table 1), all of which may impact response to treatment and some of which are interdependent. These include factors related to morphology and anatomy, the type of tissue that is affected, the presence of co-morbidities, and the clinical presentation.

The identification of patient profiles will necessarily involve the use of biomarkers and imaging markers, as has been discussed previously by the ESCEO $[4,5]$. Although there are a number of promising candidates for biomarkers
Table 1 Possible factors influencing patient profile in osteoarthritis, which might also affect response to treatment

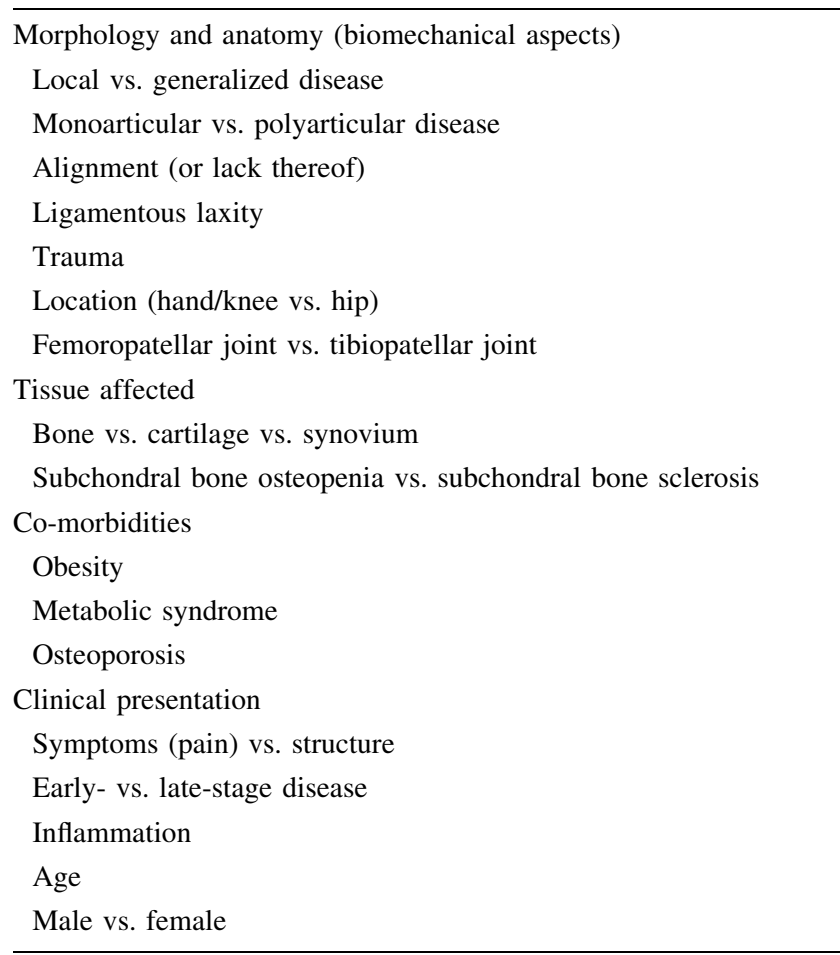

$[5,33,34]$, such as urinary C-terminal telopeptide of collagen type II (CTX-II) and serum cartilage oligomeric protein (COMP), none is sufficiently discriminating for diagnosis or prediction of prognosis in patients or for use as a surrogate outcome in clinical trials. As regards imaging, radiographic joint space width or narrowing remain the recommended parameters according to the regulatory bodies [35]. On the other hand, MRI markers also provide a good measure of cartilage morphometry [4, 36], meniscal damage [37], bone marrow lesion [37], and synovial effusion $[38,39]$.

\subsubsection{Profiles According to Articular Involvement: Local or Generalized Inflammation-Driven Osteoarthritis}

Generalized osteoarthritis may be a different profile from local osteoarthritis. The term 'generalized osteoarthritis' is widely used in the literature with a variety of conflicting definitions [40]. In the context of our discussion, we consider generalized osteoarthritis as representing a systemic disease affecting a number of different joints at the same time, i.e., it is polyarticular. This is a feature of osteoarthritis co-morbid with inflammation or the metabolic syndrome. On the other hand, local osteoarthritis occurs in a single joint, i.e., it is monoarticular, and is typical of posttraumatic osteoarthritis. It could be surmised that biological markers would be more suitable for identification of the profile of generalized osteoarthritis, while imaging markers 
would be more effective for exploration of local effects post-trauma. Similarly, within the range of biomarkers, serum measurements may provide a better measure of generalized osteoarthritis (cartilage and bone sources), while intra-articular biomarkers may better characterize local osteoarthritis [41, 42]. Ongoing genetic studies in more than 2,500 patients with generalized osteoarthritis are set to detect linkage of circulating biomarkers to osteoarthritis-associated genes, and may shed further light on the possibilities of genetic profiling for the disease [43]. There is contradictory evidence surrounding the role of inflammation, with reports that serum high-sensitivity C-reactive protein may or may not be associated with structural progression and symptoms [44-48]. An alternative explanation is that this is related to a high body mass index or the presence of the metabolic syndrome.

\subsubsection{Early Versus Late: Profiles According to Structural Damage and Response to Treatment}

Patients in the early stages of osteoarthritis, i.e., those with less severe disease, may have a separate profile from patients with advanced osteoarthritis, i.e., those with very severe disease. This is an important point since there is evidence that response to treatment may depend on a number of factors related to severity, e.g., extent of structural damage or the site of osteoarthritis (hand, knee, or hip). A dedicated PubMed search using "predictor" as a MeSH term yielded 13 studies on predictors of response in knee osteoarthritis (Table 2) (including five studies in a single systematic review on steroid injection) [49-57]. All of the studies involved assessment of structure via radiography, usually with some evaluation of symptoms. They cover a wide variety of potential treatments including doxycycline, weight loss, cindunistat, corticosteroid injection, chondroitin sulphate, glucosamine, and celecoxib. The overall conclusion from the studies is that patients with the least severe knee osteoarthritis (i.e., those with the largest joint space width early disease or with a low KL grade) are more likely to benefit from effective treatment than those with more severe disease (a smaller joint space width or higher KL grade). This implies that the most powerful predictor of treatment response is severity of osteoarthritis, with the least symptomatic patients, i.e., those with early stage disease, likely to have the best response to treatment. Patients with more advanced osteoarthritis, with extensive structural damage to the joint or malalignment, appear less likely to respond.

There are a number of methodological issues with the studies included in Table 2 (e.g., heterogeneity of the data, small studies, low statistical power, placebo effects,

Table 2 Studies in knee osteoarthritis assessing predictors of response to treatment

\begin{tabular}{|c|c|c|c|c|}
\hline References & Treatment being tested & $\begin{array}{l}\text { Patients; } \\
\text { duration }\end{array}$ & $\begin{array}{l}\text { Main } \\
\text { evaluation }\end{array}$ & Conclusion \\
\hline $\begin{array}{l}\text { Mazzuca } \\
\text { et al. [49] }\end{array}$ & Doxycycline & $\begin{array}{l}379 \text { patients; } 16 \\
\text { months }\end{array}$ & Radiography & $\begin{array}{l}\text { Patients with neutral joint structure at baseline respond } \\
\text { better to treatment than those with varus malalignment }\end{array}$ \\
\hline $\begin{array}{r}\text { Gudbergsen } \\
\text { et al. [50] }\end{array}$ & Weight loss & $\begin{array}{l}30 \text { patients; } \\
32 \text { weeks }\end{array}$ & $\begin{array}{l}\text { MRI/ } \\
\text { radiography }\end{array}$ & $\begin{array}{l}\text { Baseline joint structure did not correlate with symptomatic } \\
\text { progression }\end{array}$ \\
\hline $\begin{array}{r}\text { Gudbergsen } \\
\text { et al. [51] }\end{array}$ & Weight loss & $\begin{array}{l}175 \text { patients; } 16 \\
\text { weeks }\end{array}$ & $\begin{array}{l}\text { MRI/ } \\
\text { radiography }\end{array}$ & $\begin{array}{l}\text { Radiographic grade did not predict response to } \\
\text { symptomatic relief }\end{array}$ \\
\hline $\begin{array}{l}\text { Hellio le } \\
\text { Graverand } \\
\text { et al. [52] }\end{array}$ & Cindunistat & $\begin{array}{l}1,457 \text { patients; } \\
2 \text { years }\end{array}$ & Radiography & $\begin{array}{l}\text { Patients with less severe } \mathrm{OA}(\mathrm{KL} \text { grade } 2) \text { at baseline were } \\
\text { more responsive to treatment than those with more severe } \\
\text { disease (KL grade } 3 \text { ) }\end{array}$ \\
\hline $\begin{array}{l}\text { Maricar } \\
\text { et al. [53] }\end{array}$ & Corticosteroids & $\begin{array}{l}\text { Systematic } \\
\text { review (5 } \\
\text { studies) }\end{array}$ & Radiography & $\begin{array}{l}\text { Radiographic severity was a predictor ( } 2 \text { studies): the more } \\
\text { severe the OA, the less likely the patient was to have } \\
\text { symptomatic response } \\
\text { Radiographic OA grading did not predict response ( } 2 \\
\text { studies) } \\
\text { Arthroscopic cartilage grading was not linked to response } \\
\text { ( } 1 \text { study) }\end{array}$ \\
\hline $\begin{array}{l}\text { Sawitzke } \\
\text { et al. [54] }\end{array}$ & $\begin{array}{l}\text { Chondroitin sulphate, } \\
\text { glucosamine, and } \\
\text { celecoxib }\end{array}$ & $\begin{array}{l}572 \text { patients; } \\
2 \text { years }\end{array}$ & Radiography & $\begin{array}{l}\text { Patients with mild OA (KL grade } 2 \text { ) at baseline responded } \\
\text { better to treatment than patients with higher KL grade }\end{array}$ \\
\hline $\begin{array}{l}\text { Bennett } \\
\text { et al. [55] }\end{array}$ & Glucosamine sulphate & $\begin{array}{l}39 \text { patients; } \\
12 \text { weeks }\end{array}$ & Radiography & $\begin{array}{l}\text { Patients with less severe OA at baseline had a better } \\
\text { symptomatic response to treatment }\end{array}$ \\
\hline $\begin{array}{l}\text { Bruyère } \\
\text { et al. }[56,57]\end{array}$ & Glucosamine sulphate & $\begin{array}{l}212 \text { patients; } \\
3 \text { years }\end{array}$ & Radiography & $\begin{array}{l}\text { Patients with less severe OA at baseline had the most } \\
\text { dramatic progression of disease }\end{array}$ \\
\hline
\end{tabular}

$K L$ Kellgren-Lawrence, $M R I$ magnetic resonance imaging, $O A$ osteoarthritis 
regression to the mean, confounding factors, ceiling effects with the use of radiography, and collider bias). These observations therefore require careful interpretation and further research to ascertain the validity of any conclusion.

\subsubsection{Profiles According to the Biomechanical Properties of the Joint}

There is an increasing weight of evidence that biomechanical aspects may affect the incidence and progression of osteoarthritis [58, 59]. One example of this comes from an MRI study, which indicated that the presence of cam deformity femoroacetabular impingement appeared to predict the onset of hip osteoarthritis [60]. The most important contributors to progression appear to be joint malalignment, loss of meniscal function, and ligament injury, and so it is likely that the same biomechanical aspects could also determine response to treatment. Other mechanical factors such as joint injury, obesity, and sport may also play a role [61, 62]. This raises the possibility of different profiles according to joint morphology and biomechanical function.

Biomechanical factors should be taken into account in the management of osteoarthritis. For example, correction of malalignment using a wedge insole has been reported to be highly effective in relieving pain and function in valgus knee osteoarthritis [63]. Similarly, use of a medial collagen meniscus implant in patients with meniscus injuries was shown to improve pain, activity, and radiological outcomes over 10 years compared with patients with partial medial meniscectomy [64]. There is also evidence that deformity or malalignment could have an effect on the efficacy of treatments for osteoarthritis. In one of the studies in Table 2, patients with neutral joint structure at baseline responded better to the structural effects of treatment with doxycycline than those with varus malalignment [49].

\subsubsection{Profiles According to the Role of the Subchondral Bone}

There is evidence that there are two separate patient profiles related to lesions in the subchondral bone. Although alterations in the subchondral bone appear to play a crucial role in the development and progression of osteoarthritis [65], the literature on the relationship between osteoarthritis and osteoporosis remains mixed on the subject [66-68]. We should recall that despite increase bone volume fraction, subchondral bone is hypomineralized and of inferior quality in osteoarthritis. One hypothesis is that the subchondral bone remodeling observed in osteoarthritis is different from that in osteoporosis [69, 70]: increased bone mineral density (i.e., increased bone formation) is associated with subchondral bone sclerosis, while decreased bone mineral density (i.e., increased resorption) is associated with subchondral bone osteopenia. Animal experiments indicate that osteoporosis aggravates the progression and severity of osteoarthritis [71, 72], possibly due to subchondral bone fragility $[73,74]$.

The presence of two patient profiles may have direct implications for the effect of bone-active treatments in osteoarthritis. Indeed, response to treatment may vary according to whether the subchondral bone lesion has a sclerosis phenotype or an osteoporotic phenotype [75, 76], and patients with the osteoporotic profile could gain more benefit from bone-active treatments [69, 77-79]. More research into this is necessary, especially since varying results have been found with antiresorptive agents in osteoarthritis [80, 81]. On the other hand, subchondral bone mineral density should be assessed in osteoporosis patients with other risk factors for osteoarthritis in order to establish an early treatment [76].

\section{Discussion}

Osteoarthritis is a complex disease with varying influences on its natural history. There is currently a strong promise of therapeutic intervention. A range of factors affect its pathogenesis, presentation, and prognosis: joint morphology and anatomy, the specific type of tissue affected, the presence of co-morbidities, and the clinical presentation (Table 2). All of these factors could have an impact on response to symptomatic or structural treatments for osteoarthritis, leading to the possibility that different patient profiles have differing responses. Further research is necessary in the field before this can be applied in clinical practice.

We have explored the various possible patient profiles in osteoarthritis. The most logical pair of profiles is generalized osteoarthritis (i.e., polyarticular or systemic disease, which may be linked to inflammatory disorders or the metabolic syndrome) and local osteoarthritis (i.e., monoarticular, which is more likely in post-trauma patients or in cases of malalignment). While this separation is clear in clinical practice, i.e., the post-trauma patient presents very differently from the metabolic syndrome patient, whether they respond in the same manner to pharmacological treatments for osteoarthritis remains an issue for the research agenda.

By contrast, there is some evidence that patients with early disease respond better to pharmacological treatments for osteoarthritis than those with late disease. Further research is essential to validate these findings in light of a variety of methodological issues such as statistical power and collider bias. Another confounder may be the observation that patients with the most pain are more likely to 
receive treatment. Interestingly, patients with obesity have higher levels of pain for the same level of structural damage [82], which suggests that they too may respond differently to treatment. The separation into early and late profiles does have some weight, insofar as late-stage disease, in which joint morphology is the most affected, is best managed with surgical intervention rather than pharmacologically.

Further research into the role of the subchondral bone is likely to confirm the separation of patient profiles according to subchondral bone osteopenia or sclerosis. This is important in the light of a possible impact on response to bone-active treatments in osteoarthritis.

Treatment decisions should be made considering clinical presentation, underlying pathophysiology (function or structure, the presence of inflammation, the metabolic syndrome, adiposity, X-ray damage, functional impairment, and co-morbidities), and the stage of disease (early vs. late). In a future paper, the ESCEO group will explore how the various therapeutic options can be expected to act on the patient profiles in Table 2. This in turn will lead to more personalized healthcare, with targeted treatment for osteoarthritis.

Author Contributions OB, CC, and J-YR organized the meeting. OB, CC, NA, MH, TMA, and ED performed the literature review. All authors have taken part in the discussion and meeting and have critically analyzed and approved the final manuscript.

Acknowledgments This meeting was founded by the European Society for Clinical and Economics Aspects of Osteoporosis and Osteoarthritis, a not-for-profit organization from Belgium.

Conflicts of Interests Prof. Bruyère has received personal fees and grants from Bayer, IBSA, Genevrier, Merck Sharp \& Dohme (MSD), Novartis, Nutraveris, Pfizer, Rottapharm, Servier, SMB, and Theramex.

Prof. Cooper has received consultancy, lecture fees, and honoraria from AMGEN, GSK, Alliance for Better Bone Health, MSD, Eli Lilly, Pfizer, Novartis, Servier, Merck, Medtronic, and Roche.

Prof. Arden has received consultancy, grants, and lecture fees from Flexion (PharmaNet), Lily, Merck, Q-Med, Roche, Smith\&Nephew, Novartis, Pfizer, Schering-Plough, Servier, Amgen, GlaxoSmithKline (GSK), and NiCox.

Prof. Brandi has received grants from Amgen, Eli Lilly, MSD, Novartis, Roche, and Servier.

Prof. Berenbaum declared having received board membership from Pfizer, AbbVie, MerckSerono, Servier, Expanscience, Sanofi, UCB, and Novartis, and grants and lectures fees from Rottapharm, Servier, Pierre Fabre, Expanscience, and TRB Chemedica.

Dr Dennison has reported speaker's fees from Lilly.

Prof. Hochberg has received consultancy and lecture fees from Iroko Pharmaceuticals, Pfizer, and Bioiberica SA and declared having stock options in Theralogix LLC.

Prof. Kanis has received grants and personal fees from AgNovos Healthcare USA, Amgen, D3A, Lilly, Medimaps, Unigene, Medtronic, Novartis, Pfizer, Sanofi-Aventis, Servier, and Warner-Chilcott, and non-financial support from Asahi.
Prof. McAlindon declared having received board membership from OARSI and ACR, consultancy and grants from Sanofi Aventis, Samumed, Flexion, Fidia, and NIH, and patents and royalties from the Boston University Medical School.

Dr Reiter declared having no conflicts of interests.

Prof. Richette has received lecture fees from Ibsa, Fidia, Genevier, Expanscience, and Servier.

Prof. Rizzoli declared having received board membership, consultancy, lecture fees, and reimbursements for travel expenses from Amgen, Servier, Danone, GSK, and MSD.

Prof. Reginster has received consultancy, grants, and lecture fees from Servier, Novartis, Negma, Lilly, Wyeth, Amgen, GlaxoSmithKline, Roche, Merckle, Nycomed-Takeda, NPS, IBSA-Genevrier, Theramex, UCB, Asahi Kasei, Bristol Myers Squibb, MSD, Rottapharm, Teva, Pfizer, Danone, Organon, Therabel, Boehringer, Chiltern, Galapagos, IBSA, Genevrier, Teijin, Ebewee Pharma, Sodiac, Analis, Novo-Nordisk, Merckle, and Will Pharma.

Prof. Branco, Prof. Herrero-Beaumont, Prof. Berenbaum, Dr Dennison, Prof. Devogelaer, Dr Laslop, Prof. McAlindon, and Prof. Richette have received reimbursement for travel expenses to the meeting for the study.

Open Access This article is distributed under the terms of the Creative Commons Attribution Noncommercial License which permits any noncommercial use, distribution, and reproduction in any medium, provided the original author(s) and the source are credited.

\section{References}

1. Roman-Blas JA, Castaneda S, Largo R, et al. Osteoarthritis associated with estrogen deficiency. Arthritis Res Ther. 2009;11: 241.

2. Herrero-Beaumont G, Roman-Blas JA, Castaneda S, et al. Primary osteoarthritis no longer primary: three subsets with distinct etiological, clinical, and therapeutic characteristics. Semin Arthritis Rheum. 2009;39:71-80.

3. Cooper C, Adachi JD, Bardin T, et al. How to define responders in osteoarthritis. Curr Med Res Opin. 2013;29:719-29.

4. Pelletier JP, Cooper C, Peterfy C, et al. What is the predictive value of MRI for the occurrence of knee replacement surgery in knee osteoarthritis? Ann Rheum Dis. 2013;72:1594-604.

5. Lotz M, Martel-Pelletier J, Christiansen C, et al. Value of biomarkers in osteoarthritis: current status and perspectives. Ann Rheum Dis. 2013;72:1756-63.

6. Karsdal MA, Christiansen C, Ladel C, et al. Osteoarthritis-a case for personalized health care? Osteoarthritis Cartilage. 2014;22:7-16.

7. Bijlsma JW, Berenbaum F, Lafeber FP. Osteoarthritis: an update with relevance for clinical practice. Lancet. 2011;377:2115-26.

8. Castaneda S, Roman-Blas JA, Largo R, et al. Osteoarthritis: a progressive disease with changing phenotypes. Rheumatology (Oxford). 2014;53:1-3.

9. Kinds MB, Marijnissen AC, Bijlsma JW, et al. Quantitative radiographic features of early knee osteoarthritis: development over 5 years and relationship with symptoms in the CHECK cohort. J Rheumatol. 2013;40:58-65.

10. Kellgren JH, Lawrence JS. Radiological assessment of osteoarthrosis. Ann Rheum Dis. 1957;16:494-502.

11. Kellgren JH, Lawrence JS. The epidemiology of chronic rheumatism: atlas of standard radiographs. 2nd ed. Oxford: Blackwell Scientific; 1963.

12. Cooper C, McAlindon T, Snow S, et al. Mechanical and constitutional risk factors for symptomatic knee osteoarthritis: 
differences between medial tibiofemoral and patellofemoral disease. J Rheumatol. 1994;21:307-13.

13. Altman R, Asch E, Bloch D, et al. Development of criteria for the classification and reporting of osteoarthritis. Classification of osteoarthritis of the knee. Diagnostic and Therapeutic Criteria Committee of the American Rheumatism Association. Arthritis Rheum. 1986;29:1039-49.

14. Prieto-Alhambra D, Judge A, Javaid MK, et al. Incidence and risk factors for clinically diagnosed knee, hip and hand osteoarthritis: influences of age, gender and osteoarthritis affecting other joints. Ann Rheum Dis. 2014;73:1659-64.

15. Oliveria SA, Felson DT, Reed JI, et al. Incidence of symptomatic hand, hip, and knee osteoarthritis among patients in a health maintenance organization. Arthritis Rheum. 1995;38:1134-41.

16. van Saase JL, van Romunde LK, Cats A, et al. Epidemiology of osteoarthritis: Zoetermeer survey. Comparison of radiological osteoarthritis in a Dutch population with that in 10 other populations. Ann Rheum Dis. 1989;48:271-80.

17. Culliford DJ, Maskell J, Beard DJ, et al. Temporal trends in hip and knee replacement in the United Kingdom: 1991-2006. J Bone Joint Surg Br. 2010;92:130-5.

18. Cooper C, Arden NK. Excess mortality in osteoarthritis. BMJ. 2011;342:d1407.

19. Nuesch E, Dieppe P, Reichenbach S, et al. All cause and disease specific mortality in patients with knee or hip osteoarthritis: population based cohort study. BMJ. 2011;342:d1165.

20. Lohmander LS, Felson D. Can we identify a 'high risk' patient profile to determine who will experience rapid progression of osteoarthritis? Osteoarthritis Cartilage. 2004;12(Suppl A):S49S52.

21. Bruyère $\mathrm{O}$, Cooper $\mathrm{C}$, Pavelka $\mathrm{K}$, et al. Changes in structure and symptoms in knee osteoarthritis and prediction of future knee replacement over 8 years. Calcif Tissue Int. 2013;93:502-7.

22. Bruyère $O$, Richy $F$, Reginster $J Y$. Three year joint space narrowing predicts long term incidence of knee surgery in patients with osteoarthritis: an eight year prospective follow up study. Ann Rheum Dis. 2005;64:1727-30.

23. Soni A, Kiran A, Hart DJ, et al. Prevalence of reported knee pain over twelve years in a community-based cohort. Arthritis Rheum. 2012;64:1145-52.

24. Leyland KM, Hart D, Javaid MK, et al. The natural history of radiographic knee osteoarthritis: a 14 year population-based study. Arthritis Rheum. 2012;64:2243-51.

25. Jordan KM, Arden NK, Doherty M, et al. EULAR Recommendations 2003: an evidence based approach to the management of knee osteoarthritis: report of a Task Force of the Standing Committee for International Clinical Studies Including Therapeutic Trials (ESCISIT). Ann Rheum Dis. 2003;62:114555.

26. Zhang W, Doherty M, Leeb BF, et al. EULAR evidence based recommendations for the management of hand osteoarthritis: report of a Task Force of the EULAR Standing Committee for International Clinical Studies Including Therapeutics (ESCISIT). Ann Rheum Dis. 2007;66:377-88.

27. Zhang W, Doherty M, Arden N, et al. EULAR evidence based recommendations for the management of hip osteoarthritis: report of a task force of the EULAR Standing Committee for International Clinical Studies Including Therapeutics (ESCISIT). Ann Rheum Dis. 2005;64:669-81.

28. Hochberg MC, Altman RD, April KT, et al. American College of Rheumatology 2012 recommendations for the use of nonpharmacologic and pharmacologic therapies in osteoarthritis of the hand, hip, and knee. Arthritis Care Res (Hoboken). 2012;64:465-74.

29. Zhang W, Moskowitz RW, Nuki G, et al. OARSI recommendations for the management of hip and knee osteoarthritis, part II:
OARSI evidence-based, expert consensus guidelines. Osteoarthritis Cartilage. 2008;16:137-62.

30. National Institute for Health and Clinical Excellence. Osteoarthritis: care and management in adults. 2014. http://www. nice.org.uk/guidance/cg177. Accessed 17 Dec 2014.

31. Conaghan PG, Dickson J, Grant RL. Care and management of osteoarthritis in adults: summary of NICE guidance. BMJ. 2008;336:502-3

32. European Medicines Agency. Guideline on clinical investigation of medicinal products used in the treatment of osteoarthritis. 2010. http://www.ema.europa.eu/docs/en_GB/document_library/ Scientific_guideline/2009/09/WC500003440.pdf. Accessed 25 May 2013.

33. Bauer DC, Hunter DJ, Abramson SB, et al. Classification of osteoarthritis biomarkers: a proposed approach. Osteoarthritis Cartilage. 2006;14:723-7.

34. Kraus VB, Burnett B, Coindreau J, et al. Application of biomarkers in the development of drugs intended for the treatment of osteoarthritis. Osteoarthritis Cartilage. 2011;19:515-42.

35. Conaghan PG, Hunter DJ, Maillefert JF, et al. Summary and recommendations of the OARSI FDA osteoarthritis Assessment of Structural Change Working Group. Osteoarthritis Cartilage. 2011;19:606-10.

36. Eckstein F, Kwoh CK, Boudreau RM, et al. Quantitative MRI measures of cartilage predict knee replacement: a case-control study from the Osteoarthritis Initiative. Ann Rheum Dis. 2013;72:707-14.

37. Bowers ME, Tung GA, Fleming BC, et al. Quantification of meniscal volume by segmentation of $3 \mathrm{~T}$ magnetic resonance images. J Biomech. 2007;40:2811-5.

38. Roemer FW, Guermazi A, Felson DT, et al. Presence of MRIdetected joint effusion and synovitis increases the risk of cartilage loss in knees without osteoarthritis at 30-month follow-up: the MOST study. Ann Rheum Dis. 2011;70:1804-9.

39. Guermazi A, Roemer FW, Hayashi D. Imaging of osteoarthritis: update from a radiological perspective. Curr Opin Rheumatol. 2011;23:484-91.

40. Nelson AE, Smith MW, Golightly YM, et al. "Generalized osteoarthritis": a systematic review. Semin Arthritis Rheum. 2014;43:713-20.

41. Cattano NM, Driban JB, Balasubramanian E, et al. Biochemical comparison of osteoarthritic knees with and without effusion. BMC Musculoskelet Disord. 2011;12:273.

42. Driban JB, Balasubramanian E, Amin M, et al. The potential of multiple synovial-fluid protein-concentration analyses in the assessment of knee osteoarthritis. J Sport Rehabil. 2010;19:411-21.

43. Kraus VB, Jordan JM, Doherty M, et al. The Genetics of Generalized Osteoarthritis (GOGO) study: study design and evaluation of osteoarthritis phenotypes. Osteoarthritis Cartilage. 2007;15:120-7.

44. Kerkhof HJ, Bierma-Zeinstra SM, Castano-Betancourt MC, et al. Serum $C$ reactive protein levels and genetic variation in the CRP gene are not associated with the prevalence, incidence or progression of osteoarthritis independent of body mass index. Ann Rheum Dis. 2010;69:1976-82.

45. Vlad SC, Neogi T, Aliabadi P, et al. No association between markers of inflammation and osteoarthritis of the hands and knees. J Rheumatol. 2011;38:1665-70.

46. Siebuhr AS, Petersen KK, Arendt-Nielsen L, et al. Identification and characterisation of osteoarthritis patients with inflammation derived tissue turnover. Osteoarthritis Cartilage. 2014;22:44-50.

47. van Spil WE, Nair SC, Kinds MB, et al. Systemic biochemical markers of joint metabolism and inflammation in relation to radiographic parameters and pain of the knee: data from CHECK, a cohort of early-osteoarthritis subjects. Osteoarthritis Cartilage. 2015;23:48-56. 
48. Sokolove J, Lepus CM. Role of inflammation in the pathogenesis of osteoarthritis: latest findings and interpretations. Ther Adv Musculoskelet Dis. 2013;5:77-94.

49. Mazzuca SA, Brandt KD, Chakr R, et al. Varus malalignment negates the structure-modifying benefits of doxycycline in obese women with knee osteoarthritis. Osteoarthritis Cartilage. 2010;18:1008-11.

50. Gudbergsen H, Boesen M, Christensen R, et al. Radiographs and low field MRI $(0.2 \mathrm{~T})$ as predictors of efficacy in a weight loss trial in obese women with knee osteoarthritis. BMC Musculoskelet Disord. 2011;12:56.

51. Gudbergsen H, Boesen M, Lohmander LS, et al. Weight loss is effective for symptomatic relief in obese subjects with knee osteoarthritis independently of joint damage severity assessed by high-field MRI and radiography. Osteoarthritis Cartilage. 2012;20:495-502.

52. Hellio Le Graverand MP, Clemmer RS, Redifer P, et al. A 2-year randomised, double-blind, placebo-controlled, multicentre study of oral selective iNOS inhibitor, cindunistat (SD-6010), in patients with symptomatic osteoarthritis of the knee. Ann Rheum Dis. 2013;72:187-95.

53. Maricar N, Callaghan MJ, Felson DT, et al. Predictors of response to intra-articular steroid injections in knee osteoarthritisa systematic review. Rheumatology (Oxford). 2013;52:1022-32.

54. Sawitzke AD, Shi H, Finco MF, et al. The effect of glucosamine and/or chondroitin sulfate on the progression of knee osteoarthritis: a report from the glucosamine/chondroitin arthritis intervention trial. Arthritis Rheum. 2008;58:3183-91.

55. Bennett AN, Crossley KM, Brukner PD, et al. Predictors of symptomatic response to glucosamine in knee osteoarthritis: an exploratory study. Br J Sports Med. 2007;41:415-9.

56. Bruyère $\mathrm{O}$, Honore $\mathrm{A}$, Rovati $\mathrm{LC}$, et al. Radiologic features poorly predict clinical outcomes in knee osteoarthritis. Scand J Rheumatol. 2002;31:13-6.

57. Bruyère $\mathrm{O}$, Honore $\mathrm{A}$, Ethgen $\mathrm{O}$, et al. Correlation between radiographic severity of knee osteoarthritis and future disease progression. Results from a 3-year prospective, placebo-controlled study evaluating the effect of glucosamine sulfate. Osteoarthritis Cartilage. 2003;11:1-5.

58. Englund M. The role of biomechanics in the initiation and progression of OA of the knee. Best Pract Res Clin Rheumatol. 2010;24:39-46.

59. Tanamas S, Hanna FS, Cicuttini FM, et al. Does knee malalignment increase the risk of development and progression of knee osteoarthritis? A systematic review. Arthritis Rheum. 2009;61:459-67.

60. Pfirrmann CW, Mengiardi B, Dora C, et al. Cam and pincer femoroacetabular impingement: characteristic MR arthrographic findings in 50 patients. Radiology. 2006;240:778-85.

61. Richmond SA, Fukuchi RK, Ezzat A, et al. Are joint injury, sport activity, physical activity, obesity, or occupational activities predictors for osteoarthritis? A systematic review. J Orthop Sports Phys Ther. 2013;43:515-B19.

62. Nicholls AS, Kiran A, Javaid MK, et al. Change in body mass index during middle age affects risk of total knee arthoplasty due to osteoarthritis: a 19-year prospective study of 1003 women. Knee. 2012;19:316-9.

63. Rodrigues PT, Ferreira AF, Pereira RM, et al. Effectiveness of medial-wedge insole treatment for valgus knee osteoarthritis. Arthritis Rheum. 2008;59:603-8.

64. Zaffagnini S, Marcheggiani Muccioli GM, Lopomo N, et al. Prospective long-term outcomes of the medial collagen meniscus implant versus partial medial meniscectomy: a minimum 10-year follow-up study. Am J Sports Med. 2011;39:977-85.
65. Huebner JL, Bay-Jensen AC, Huffman KM, et al. Alpha C-telopeptide of type I collagen is associated with subchondral bone turnover and predicts progression of joint space narrowing and osteophytes in osteoarthritis. Arthritis Rheumatol. 2014;66: 2440-9.

66. Sharma AR, Jagga S, Lee SS, et al. Interplay between cartilage and subchondral bone contributing to pathogenesis of osteoarthritis. Int J Mol Sci. 2013;14:19805-30.

67. Goldring SR, Goldring MB. Bone and cartilage in osteoarthritis: is what's best for one good or bad for the other? Arthritis Res Ther. 2010;12:143.

68. Radin EL, Rose RM. Role of subchondral bone in the initiation and progression of cartilage damage. Clin Orthop Relat Res. 1986;(213):34-40.

69. Herrero-Beaumont G, Roman-Blas JA. Osteoarthritis: Osteoporotic OA: a reasonable target for bone-acting agents. Nat Rev Rheumatol. 2013;9:448-50.

70. Carrino JA, Blum J, Parellada JA, et al. MRI of bone marrow edema-like signal in the pathogenesis of subchondral cysts. Osteoarthritis Cartilage. 2006;14:1081-5.

71. Castaneda S, Largo R, Calvo E, et al. Effects of estrogen deficiency and low bone mineral density on healthy knee cartilage in rabbits. J Orthop Res. 2010;28:812-8.

72. Calvo E, Castaneda S, Largo R, et al. Osteoporosis increases the severity of cartilage damage in an experimental model of osteoarthritis in rabbits. Osteoarthritis Cartilage. 2007;15:69-77.

73. Bellido M, Lugo L, Roman-Blas JA, et al. Subchondral bone microstructural damage by increased remodelling aggravates experimental osteoarthritis preceded by osteoporosis. Arthritis Res Ther. 2010;12:R152.

74. Bellido M, Lugo L, Roman-Blas JA, et al. Improving subchondral bone integrity reduces progression of cartilage damage in experimental osteoarthritis preceded by osteoporosis. Osteoarthritis Cartilage. 2011;19:1228-36.

75. Wang SX, Laverty S, Dumitriu M, et al. The effects of glucosamine hydrochloride on subchondral bone changes in an animal model of osteoarthritis. Arthritis Rheum. 2007;56:153748.

76. Roman-Blas JA, Castaneda S, Largo R, et al. An OA phenotype may obtain major benefit from bone-acting agents. Semin Arthritis Rheum. 2014;43:421-8.

77. Carbone LD, Nevitt MC, Wildy K, et al. The relationship of antiresorptive drug use to structural findings and symptoms of knee osteoarthritis. Arthritis Rheum. 2004;50:3516-25.

78. Karsdal MA, Bay-Jensen AC, Lories RJ, et al. The coupling of bone and cartilage turnover in osteoarthritis: opportunities for bone antiresorptives and anabolics as potential treatments? Ann Rheum Dis. 2014;73:336-48.

79. Karsdal MA, Leeming DJ, Dam EB, et al. Should subchondral bone turnover be targeted when treating osteoarthritis? Osteoarthritis Cartilage. 2008;16:638-46.

80. Davis AJ, Smith TO, Hing CB, et al. Are bisphosphonates effective in the treatment of osteoarthritis pain? A meta-analysis and systematic review. PLoS One. 2013;8:e72714.

81. Laslett LL, Kingsbury SR, Hensor EM, et al. Effect of bisphosphonate use in patients with symptomatic and radiographic knee osteoarthritis: data from the Osteoarthritis Initiative. Ann Rheum Dis. 2014;73:824-30.

82. Goulston LM, Kiran A, Javaid MK, et al. Does obesity predict knee pain over fourteen years in women, independently of radiographic changes? Arthritis Care Res (Hoboken). 2011;63: 1398-406. 